\title{
A siphonous morphology affects light-harvesting modulation in the intertidal green macroalga Bryopsis corticulans (Ulvophyceae)
}

\author{
Vasco Giovagnetti ${ }^{1}$. Guangye $\mathrm{Han}^{2} \cdot$ Maxwell A. Ware ${ }^{1} \cdot$ Petra Ungerer $^{1} \cdot$ Xiaochun Qin $^{2} \cdot$ Wen-Da Wang $^{2}$. \\ Tingyun Kuang ${ }^{2} \cdot$ Jian-Ren Shen ${ }^{2,3} \cdot$ Alexander V. Ruban $^{1}$
}

Received: 21 November 2017 / Accepted: 20 January 2018 / Published online: 19 February 2018

(c) The Author(s) 2018. This article is an open access publication

\begin{abstract}
Main conclusion The macroalga Bryopsis corticulans relies on a sustained protective NPQ and a peculiar body architecture to efficiently adapt to the extreme light changes of intertidal shores.

During low tides, intertidal algae experience prolonged high light stress. Efficient dissipation of excess light energy, measured as non-photochemical quenching (NPQ) of chlorophyll fluorescence, is therefore required to avoid photodamage. Lightharvesting regulation was studied in the intertidal macroalga Bryopsis corticulans, during high light and air exposure. Photosynthetic capacity and NPQ kinetics were assessed in different filament layers of the algal tufts and in intact chloroplasts to unravel the nature of NPQ in this siphonous green alga. We found that the morphology and pigment composition of the B. corticulans body provides functional segregation between surface sunlit filaments (protective state) and those that are underneath and undergo severe light attenuation (light-harvesting state). In the surface filaments, very high and sustained NPQ gradually formed. NPQ induction was triggered by the formation of transthylakoid proton gradient and independent of the xanthophyll cycle. PsbS and LHCSR proteins seem not to be active in the NPQ mechanism activated by this alga. Our results show that $B$. corticulans endures excess light energy pressure through a sustained protective NPQ, not related to photodamage, as revealed by the unusually quick restoration of photosystem II (PSII) function in the dark. This might suggest either the occurrence of transient PSII photoinactivation or a fast rate of PSII repair cycle.
\end{abstract}

Keywords Bryopsis corticulans $\cdot$ Intertidal algae $\cdot$ Light harvesting $\cdot$ LHCSR $\cdot$ Non-photochemical quenching $\cdot$ PsbS

Vasco Giovagnetti and Guangye Han contributed equally to this work.

Jian-Ren Shen

shen@cc.okayama-u.ac.jp

$\triangle$ Alexander V. Ruban

a.ruban@qmul.ac.uk

1 School of Biological and Chemical Sciences, Queen Mary University of London, Mile End Road, London E1 4NS, UK

2 Photosynthesis Research Center, Key Laboratory of Photobiology, Institute of Botany, Chinese Academy of Sciences, Beijing 100093, China

3 Research Institute for Interdisciplinary Science, Graduate School of Natural Science and Technology, Okayama University, 3-1-1 Tsushima, Naka, Okayama 700-8530, Japan

\section{Introduction}

Oxygenic photosynthesis uses sunlight energy to convert carbon dioxide and water into carbohydrates and molecular oxygen, through the transfer of electrons between photosystems II and I (PSII and PSI) (Blankenship 2014). This process generates an electrochemical proton gradient across the thylakoid membranes that is used for the synthesis of adenosine triphosphate (ATP) and reduced nicotinamide adenine dinucleotide phosphate (NADPH), and feedback modulation of light harvesting (Cardol et al. 2011).

Photosynthetic light energy conversion takes place in PSII and I, multi-subunit pigment-protein complexes that are embedded in the thylakoid membrane. These complexes are composed of a core complex, containing the reaction centre (RC) and inner antenna complexes, and a lightharvesting complex (LHC) or peripheral antenna, built of many pigment-protein complexes (Ruban et al. 2012; Croce 
and van Amerongen 2014). While RCs are responsible for charge separation and electron transfer, light-harvesting antennae are specialised to absorb light in a wide spectral range and increase the effective absorption cross section of RCs. Despite the fact that RCs of PSII and PSI differ from each other (Amunts et al. 2007; Umena et al. 2011; Qin et al. 2015a; Suga et al. 2015), the individual photosystems and their core antennae are highly conserved in all oxygen-evolving organisms (Blankenship et al. 2007; Hohmann-Marriott and Blankenship 2011). In contrast, peripheral light-harvesting systems are modular units diversified among photosynthetic groups of organisms. These systems display marked differences in pigment-protein composition/organisation and size to match the diversity in light intensity and quality of different habitats (Falkowski and Raven 2007; Ruban et al. 2011; Ballottari et al. 2012; Blankenship 2014).

Sudden and extreme changes in light intensity and quality that occur in nature affect photosynthetic rates. When light energy is absorbed in excess, it can oversaturate the electron transport chain capacity and associated enzyme-catalysed reactions without driving photochemistry. This increases the chance of photo-oxidative damage (Aro et al. 1993; Ruban et al. 2012). Under high light, the concurrent presence of excess excitation energy and $\mathrm{O}_{2}$ within the photosynthetic membranes can yield reactive oxygen species (e.g. singlet oxygen) due to the transfer of energy from chlorophyll (Chl) triplet states $\left({ }^{3} \mathrm{Chl}{ }^{*}\right)$ to $\mathrm{O}_{2}$, ultimately causing photoinhibition (Aro et al. 1993; Tyystjärvi and Aro 1996; Giovagnetti and Ruban 2015). Photosynthetic organisms have developed sophisticated mechanisms to cope with fluctuating light environments and reduce the accumulation of detrimental excess light energy, thus balancing the input and utilisation of sunlight in photosynthesis ( $\mathrm{Li}$ et al. 2009; Goss and Lepetit 2015; Ruban 2016).

The fastest and reversible process activated to protect against high light can be measured at room temperature as a decline in PSII antenna Chl fluorescence yield and is referred to as non-photochemical quenching of Chl fluorescence (NPQ) (Ruban 2016). Although NPQ is essential and common to all photosynthetic organisms, clear differences in the underlying mechanisms have been observed (see Demmig-Adams et al. 2014; Goss and Lepetit 2015; Ruban 2016). Overall, NPQ reflects a number of mechanistically different processes, namely: energy-dependent (qE), state-transition (qT), photoinhibitory (qI) and zeaxanthindependent (qZ) quenching components (Krause and Weis 1991; Ruban et al. 2012; Demmig-Adams et al. 2014; Goss and Lepetit 2015; Ruban 2016). While kinetic criteria are usually employed to discern between them (i.e. times of formation and relaxation), it has been recently underlined how this approach can give misleading interpretations if we are to investigate their effective protective nature (Ruban and Murchie 2012; Giovagnetti and Ruban 2015).
$\mathrm{qE}$ is the largest and fastest response to light intensity changes (forming and recovering within minutes) and it is often the most effective in protecting PSII RCs against photodamage (Ruban and Murchie 2012; Demmig-Adams et al. 2014; Goss and Lepetit 2015; Ruban 2016). It depends on the generation of a transthylakoid proton gradient $(\Delta \mathrm{pH}$, Krause and Behrend 1986; Noctor et al. 1993), and in vascular plants it is controlled by the activation of the protein PSII subunit S (PsbS) through the acidification of the thylakoid lumen ( $\mathrm{Li}$ et al. 2000, 2004) and the operation of the (violaxanthin-antheraxanthin-zeaxanthin) xanthophyll cycle (XC, Yamamoto and Kamite 1972; Yamamoto 1979). Both PsbS and zeaxanthin act as allosteric modulators that enhance the sensitivity of PSII antenna to lumenal protons and regulate antenna conformational changes (Ruban et al. 2012; Sacharz et al. 2017). The presence of specific polypeptides and the XC involvement in NPQ vary among the eukaryotic photosynthetic lineages so far studied. In the green alga Chlamydomonas reinhardtii, the stress-related members of the LHC protein superfamily, LHCSR3 and LHCSR1, were proposed to play the roles of $\mathrm{pH}$ sensor and active site of quenching (Peers et al. 2009; Bonente et al. 2011; Ballottari et al. 2016; Dinc et al. 2016), while PsbS was quickly and transiently accumulated (Tibiletti et al. 2016). Whereas both PsbS and LHCSR are active during NPQ in the moss Physcomitrella patens (Alboresi et al. 2010), some of the LHCX isoforms, related to the LHCSR protein family, are involved in the modulation of excess energy dissipation in the diatom Phaeodactylum tricornutum (Bailleul et al. 2010; Lepetit et al. 2013, 2016; Taddei et al. 2016). Whilst the role of de-epoxidation of violaxanthin into zeaxanthin is still debated in C. reinhardtii (Bonente et al. 2011; Dinc et al. 2016), NPQ has often been reported to be XC activation dependent in mosses (Pinnola et al. 2013) and diatoms (the latter contain the diadinoxanthin-diatoxanthin XC as the main XC; see Goss and Lepetit 2015).

In this study, we investigated the regulation of light harvesting in the marine green alga Bryopsis corticulans (class Ulvophyceae, order Bryopsidales) (Graham and Wilcox 2000; Lam and Zechman 2006; Verbruggen et al. 2009). B. corticulans algae typically flourish in rocky intertidal shores during summer, where they are adapted to extreme light fluctuations and variations in other abiotic environmental factors (e.g. temperature, inorganic carbon and nutrient availability) due to the seasonal tidal rhythm (Davison and Pearson 1996; Gómez and Huovinen 2011; Hurd et al. 2014). This species is able to survive repeated and prolonged periods either underwater $(\sim 1-2 \mathrm{~m})$ at low/moderate light or exposed to the atmosphere at very high light. This must therefore require fine-tuning of the light-harvesting capacity during the day to adapt to light limitation when submerged and prevent photo-induced damage when exposed to the atmosphere ( $\mathrm{Li}$ et al. 2009; Ruban et al. 2012; Ruban 2016). Moreover, B. corticulans response to high 
light stress occurs without the involvement of XC pigments active in NPQ (Wang et al. 2013), as reported for the algal order of Bryopsidales (Christa et al. 2017).

In line with the typically described body structure of Bryopsidales, $B$. corticulans is a macroscopic, siphonous green alga that comprises a single, giant cell with tubular filaments called 'siphons'. Its algal body (thallus) consists of a tough, flexible cell wall that surrounds a continuous cytoplasm containing multiple nuclei, discoid plastids, and other organelles (Graham and Wilcox 2000; Lam and Zechman 2006). The photosynthetic apparatus of $B$. corticulans exhibits peculiar properties when compared with that of higher plants. Although substantial differences in the composition of Chls and carotenoids have been reported between LHCII isolated from $B$. corticulans and Spinacia oleracea (Liu et al. 2004; Wang et al. 2013), their polypeptide sequences and key residues responsible for maintaining LHCII structure and function were highly conserved (Wang et al. 2013). Lutein and violaxanthin are not present in LHCII of siphonous algae; however, carotenoids with conjugated carbonyl groups, e.g. siphonaxanthin (Sx) and siphonein (S), are found together with more $\mathrm{Chl} b$ molecules, enhancing the absorption of blue-green and green light (Nakayama and Okada 1990; Chen et al. 2005, 2008; Wang et al. 2013). This is particularly advantageous when thriving in intertidal waters, where visible light is strongly attenuated, apart from the blue-green light region (Kirk 2011).

Additionally, the isolation and characterisation of a PSI-LHCI supercomplex and its sub-complexes revealed a number of unique features. Notably, B. corticulans possesses a unique $\alpha$ - and $\varepsilon$-carotene-type PSI core complex among photosynthetic eukaryotes, suggesting for the first time a structural flexibility of the PSI core (Qin et al. 2015b). Moreover, it was found that seven different carotenoids bind to the Lhca antennae, conferring a high carotenoid/Chl ratio, and less red Chls are present in the PSI-LHCI supercomplex relative to that of S. oleracea (Qin et al. 2015a, b).

Given the (1) unique pigment (and potentially protein) composition of PSII and PSI light-harvesting systems and (2) the flexible adaptation to the intertidal light environment, here we studied the light-harvesting and photoprotection modulation in B. corticulans algae during low tides and exposure to the atmosphere. The results obtained are discussed in the light of the current understanding of the NPQ molecular mechanisms revealed in other eukaryotic photosynthetic $\mathrm{O}_{2}$ evolvers.

\section{Materials and methods}

\section{Study site and collection of algae}

Bryopsis corticulans Setchell (Ulvophyceae) (Collins et al. 1899) algae populating the rocky intertidal shores of Yantai
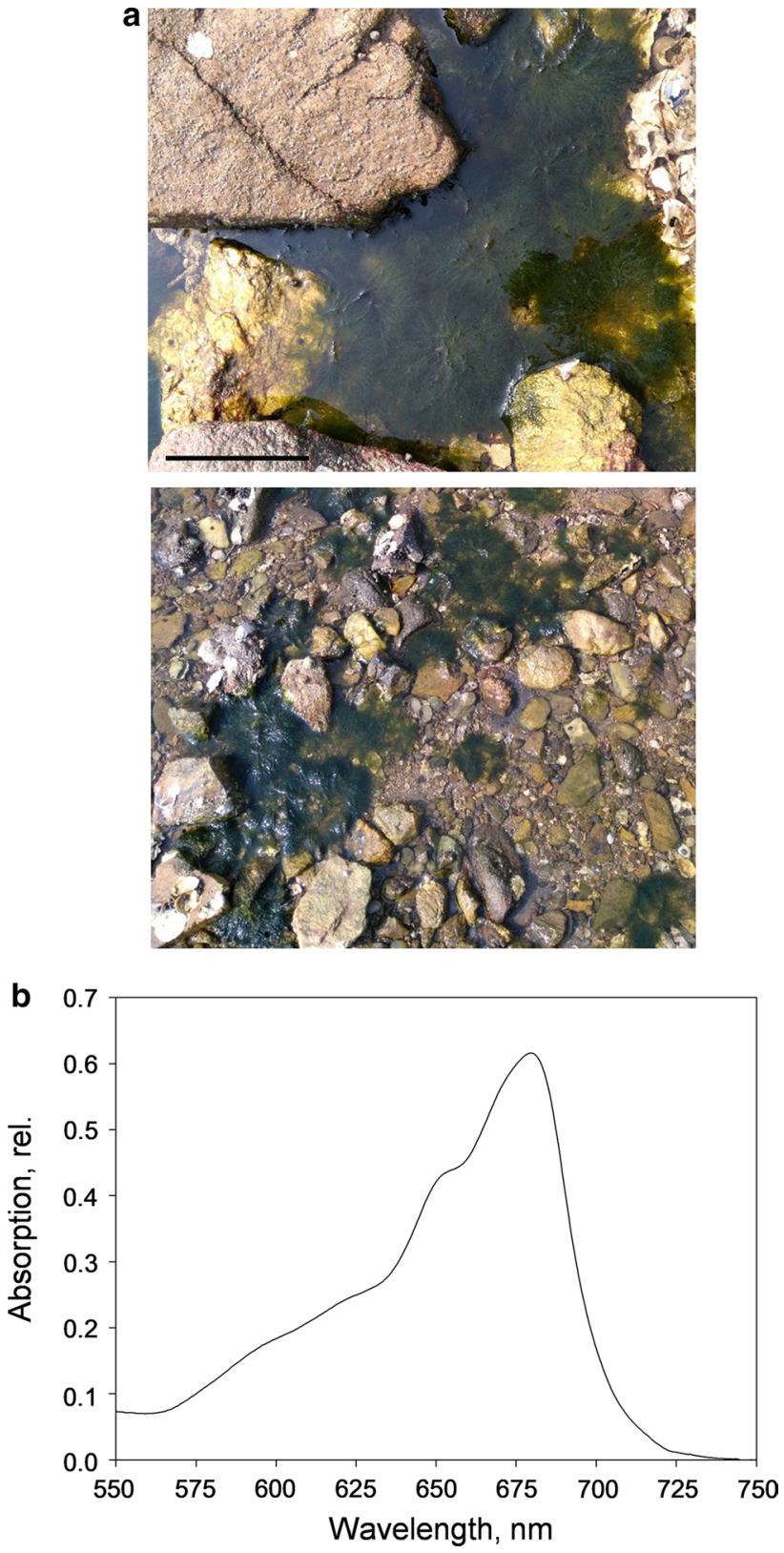

Fig. 1 B. corticulans algae during emersions due to low tides (a) and absorption capacity (b). Absorption spectra of single layers of adjacent filaments were measured at room temperature, after 30 min dark adaptation. The spectrum presented is the average of four repeats. Scale bar in $\mathbf{a}, 10 \mathrm{~cm}$

(north-eastern province of Shandong, China; $37^{\circ} 28^{\prime} 35^{\prime \prime} \mathrm{N}$, $121^{\circ} 26^{\prime} 27^{\prime \prime} \mathrm{E}$ ) were collected during summer (September 2016). Field work was carried out during low tides, causing algae to be partly or completely exposed to air (Fig. 1a). Algae were collected during the lowest tide level and measurements were taken between 11:00 and 15:00 hours, after which the water level gradually increased and algal tufts became submerged underwater $(\sim 1-2 \mathrm{~m}$ below the water surface). While algae submersions lasted until early morning 
(low or moderate light levels), the prolonged exposure to the atmosphere coincided with the highest light intensities and temperatures of the day. Experiments were carried out in the field and in the laboratory, which was in close proximity to the sampling site. For the laboratory experiments, freshly collected samples were maintained for short time periods in filtered natural seawater. After dark adaptation, samples were used to perform $\mathrm{Chl}$ fluorescence measurements and chloroplast isolation from B. corticulans.

\section{Chloroplast preparation and pigment analysis}

Intact chloroplasts were isolated after 30 min dark adaptation. All the following steps were carried out in dim light and at $4{ }^{\circ} \mathrm{C}$. Five fresh algal tufts were ground in $100 \mathrm{~mL}$ of pre-cooled homogenisation buffer (10 mM Mes pH 6.5, $2 \mathrm{mM} \mathrm{KCl,} 5 \mathrm{mM}$ EDTA, $1 \mathrm{M}$ sorbitol). Algae were ground by three consecutive cycles ( $3 \mathrm{~s}$ each) using a household blender. The homogenate was filtered through four layers of muslin, followed by four layers of muslin and one layer of cotton wool. The filtrate was centrifuged for $8 \mathrm{~min}$ at $4000 \mathrm{~g}$ $\left(4{ }^{\circ} \mathrm{C}\right)$. The supernatant was removed and the chloroplast pellet washed in a resuspension buffer (10 mM Mes pH 6.5, $2 \mathrm{mM} \mathrm{KCl}, 5 \mathrm{mM}$ EDTA, $0.33 \mathrm{M}$ sorbitol). Chloroplasts showed a high degree of intactness, as verified under the microscope, and $F_{\mathrm{v}} / F_{\mathrm{m}}$ values of $\sim 0.73$, i.e. slightly lower than values measured in $B$. corticulans filaments (see the text). Total $\mathrm{Chl}$ content and $\mathrm{Chl} a / b$ ratio were determined in $80 \%$ acetone according to Porra et al. (1989). High-performance liquid chromatography (HPLC) was performed as described in Wang et al. (2013).

\section{Absorption spectroscopy}

Absorption spectra were recorded with a Shimadzu UV-Visible 2550 spectrophotometer (Kyoto, Japan) at room temperature. Measurements were performed on single layers of adjacent filaments of (30 min) dark-adapted algae, which were carefully placed on a glass slide under the microscope. The diameter of each single filament was $0.26 \pm 0.02 \mathrm{~mm}$. Empty spaces between filaments were carefully avoided to provide a homogenous surface for the spectrophotometer beam.

\section{Chlorophyll fluorescence analysis}

Chl fluorescence was measured on B. corticulans filaments using a Walz JUNIOR-PAM fluorometer (Walz Effeltrich, Germany), equipped with a magnetic leaf clip. For the field experiments, algal tufts of $B$. corticulans were dark adapted for $30 \mathrm{~min}$ prior to their exposure to actinic light (AL). Rapid light curves were assessed using ten gradually increasing intensities of AL, each lasting $10 \mathrm{~s}$ and followed by a saturating pulse (SP). 24 repeats were taken, with error bars representing \pm SEM. Relative photosynthetic efficiency $(\alpha)$, electron transport rate (ETR) and light-saturation parameter (Ek) were calculated by the Software WinControl (Walz) fitting the model of Platt et al. (1980).

To assess the relevance of $B$. corticulans morphology to light-harvesting regulation, laboratory experiments were carried out. Chl fluorescence quenching induction and relaxation were measured on dark-adapted whole algal tufts, each one submerged in filtered seawater contained in a beaker (see Fig. 3a for a diagram). Given the static floating of the algae, a stratification of the algal body filaments was obtained along the water volume. Chl fluorescence was probed in both 'surface filaments' (exposed to the atmosphere) and 'bottom filaments' ( $2 \mathrm{~cm}$ underneath the water surface; Fig. $3 \mathrm{a}$ ). White AL (2000 $\mu$ mol photons $\left.\mathrm{m}^{-2} \mathrm{~s}^{-1}\right)$ was provided by two external light sources, whereas measuring light (ML) and $\mathrm{SP}\left(0.6 \mathrm{~s}\right.$ and $4000 \mu \mathrm{mol}$ photons $\left.\mathrm{m}^{-2} \mathrm{~s}^{-1}\right)$ were provided by two JUNIOR-PAM fibre optics, which were secured to prevent movement (Fig. 3a). The entire procedure consisted of $1 \mathrm{~h}$ of AL illumination (NPQ induction), followed by $3 \mathrm{~h}$ of recovery in the dark (NPQ relaxation). An SP was applied every 5 min during light treatment, and $10 \mathrm{~s}$ after AL was switched off, as well as every $20 \mathrm{~min}$ in the dark. For both layers, four independent measurements were performed.

Chl fluorescence was measured on $B$. corticulans intact chloroplasts with a DUAL-PAM-100 fluorometer (Walz Effeltrich, Germany), equipped with the liquid cell adapter. Measurements were carried out on $2 \mathrm{~mL}$ of intact chloroplasts (final concentration of $35 \mu \mathrm{M}$ of total $\mathrm{Chl}$ in the resuspension buffer) in a quartz cuvette. Constant, gentle stirring was applied. To induce quenching, AL intensities of $211 \mu \mathrm{mol}$ photons $\mathrm{m}^{-2} \mathrm{~s}^{-1}$ (5 min), or 760 and $2500 \mu \mathrm{mol}$ photons $\mathrm{m}^{-2} \mathrm{~s}^{-1}$ (30 min) were used. Where mentioned, $100 \mu \mathrm{M}$ nigericin or $600 \mu \mathrm{M}$ diaminodurene (DAD) was added in the dark (2 min before ML was switched on) to intact chloroplasts to prevent or increase the formation of $\Delta \mathrm{pH}$ across the thylakoid membrane, respectively (Wraight and Crofts 1970; Johnson and Ruban 2011). The use of relatively high concentration of both uncouplers was needed for effective penetration through the chloroplast surrounding membrane (Grant and Wright 1980). $\mathrm{AL}$ and SP were provided by an array of $635 \mathrm{~nm}$ light-emitting diodes. $F_{\mathrm{o}}$ and $F_{\mathrm{o}}{ }^{\prime}$ (i.e. the fluorescence level with PSII RCs open in the dark and during AL exposure) were measured in the presence of a $7 \mu$ mol photons $\mathrm{m}^{-2} \mathrm{~s}^{-1}$ measuring beam. $F_{\mathrm{s}}$ is the steady state fluorescence level under AL. The maximum fluorescence in the dark-adapted state $\left(F_{\mathrm{m}}\right)$, during the course of AL illumination $\left(F_{\mathrm{m}}{ }^{\prime}\right)$, and in the subsequent dark relaxation periods $\left(F_{\mathrm{m}}{ }^{\prime \prime}\right)$ was determined using $0.6 \mathrm{~s}$ SP of $4000 \mu \mathrm{mol}$ photons $\mathrm{m}^{-2} \mathrm{~s}^{-1}$. Maximum quantum yield of PSII in the dark was calculated as $F_{\mathrm{v}} / F_{\mathrm{m}}=\left[\left(F_{\mathrm{m}}-F_{\mathrm{o}}\right) / F_{\mathrm{m}}\right]$, photochemical quenching as $q_{\mathrm{P}}=\left(F_{\mathrm{m}}{ }^{\prime}-F_{\mathrm{s}}\right) /\left(F_{\mathrm{m}}{ }^{\prime}-F_{\mathrm{o}}{ }^{\prime}\right)$ and non-photochemical fluorescence quenching as NPQ $=\left[\left(F_{\mathrm{m}} / F_{\mathrm{m}}{ }^{\prime}\right)-1\right]$. The 
photochemical quenching measured in the dark immediately after illumination $\left(q_{\mathrm{Pd}}\right)$ was calculated as $q_{\mathrm{Pd}}=\left(F_{\mathrm{m}}{ }^{\prime}-F_{\mathrm{o}}{ }^{\prime}\right.$ act. $) /$ $\left(F_{\mathrm{m}}{ }^{\prime}-F_{\mathrm{o}}{ }^{\prime}\right.$ calc. $)$ (Ruban and Murchie 2012). $F_{\mathrm{o} \text { act. }}{ }^{\prime}$ and $F_{\mathrm{o}}{ }^{\prime}$ calc. are the measured and calculated levels of minimum fluorescence in the dark after illumination, respectively. $F_{\mathrm{o}}{ }^{\prime}$ calc. is calculated according to Oxborough and Baker (1997) as $F_{\text {o act. }}{ }^{\prime}{ }^{1 /}$ $\left(1 / F_{\mathrm{o}}-1 / F_{\mathrm{m}}+1 / F_{\mathrm{m}}{ }^{\prime}\right)$. Under high light, $F_{\mathrm{o}}{ }^{\prime}$ act. becomes greater than $F_{\mathrm{o}}{ }^{\prime}$ calc, , and $q_{\mathrm{Pd}}$ declines below 1.00 . This reflects photodamage of PSII RCs, which has been considered to occur when more than $2 \%$ of PSII RCs are closed $\left(q_{\mathrm{Pd}}<0.98\right)$ (Ruban and Murchie 2012; Giovagnetti and Ruban 2015).

\section{SDS-PAGE and western blot analysis}

To analyse potential changes in polypeptide composition upon NPQ formation/relaxation, glycine-sodium dodecyl sulphate polyacrylamide gel electrophoresis (glycine-SDSPAGE; Laemmli 1970) was used, as in Qin et al. (2015b). Stacking and separation gels of 4 and $12 \%$ acrylamide/bisacrylamide (29:1) mix, respectively, were employed. Samples were denatured with a lithium dodecyl sulphate sample buffer (Ikeuchi and Inoue 1988) at $40{ }^{\circ} \mathrm{C}$ for $10 \mathrm{~min}$, and $10 \mu \mathrm{g} \mathrm{Chl}$ of chloroplasts was loaded per lane. After electrophoresis, gels were used for electroblotting onto nitrocellulose membrane (GE Healthcare, UK) and the proteins were incubated overnight at $4{ }^{\circ} \mathrm{C}$ with antibodies raised against PsbS (Agrisera AS09533, 1:2000), LHCSR3 (Agrisera AS142766, 1:1000) and LHCSR1 (Agrisera AS142819, 1:1000). The $\beta$ subunit of ATP synthase (ATP-B, Agrisera AS05085, 1:2000) was used as loading control. Enhanced chemiluminescence (WSE-6200HLuminiGraph II chemiluminescent imaging system, ATTO, Japan) was used to visualise protein bands after incubation with a horseradish peroxidase (HRP)-conjugated secondary antibody (Agrisera AS09602, 1:20000).

\section{Statistical analysis}

Statistical significance at a $P$ value $<0.05$ was determined with Student's $t$ test, using a two-tailed distribution. Error bars represent the standard error of the mean $(\mathrm{SEM}=\mathrm{SD} / \sqrt{n})$. The results of the statistical analysis are given in the text and figure legends.

\section{Results}

\section{Photosynthetic capacity of B. corticulans algae during low tides}

Because of tidal cycles, intertidal algae experience continuous switching between air exposure and water submersion (Fig. 1a; Madsen and Maberly 1990; Davison and Pearson
1996). Exposure to the atmosphere poses problems of water loss and desiccation, nutrient availability, and very high light absorption, all factors that can ultimately impair photosynthesis and cause photodamage. We therefore investigated the photosynthetic properties and capacity of $B$. corticulans algal tufts in the field, when they partially or completely emerged from water during low tides (Fig. 1a). Measurements took place when the air light intensity and temperature reached the highest levels of the day, demanding optimisation of light harvesting (up to $\sim 2000 \mu \mathrm{mol}$ photons $\mathrm{m}^{-2} \mathrm{~s}^{-1}$ and $\sim 33{ }^{\circ} \mathrm{C}$ at midday).

A 30 min dark adaptation was found to be sufficient to relax the excess light excitation pressure encountered in nature by the $B$. corticulans algae. Indeed, a PSII maximum quantum yield in the dark $\left(F_{\mathrm{v}} / F_{\mathrm{m}}\right)$ of $0.76 \pm 0.01$ was measured. This is in agreement with values previously reported for other green macroalgae belonging to the order of Ulvales (Franklin et al. 1992; Henley et al. 1991; Henley 1992; Yamazaki et al. 2005) and Bryopsidales (Yamazaki et al. 2005; Cruz et al. 2014), as well as for several different species of Bryopsidales cultured in the laboratory under constant low light (i.e. $25 \mu$ mol photons $\mathrm{m}^{-2} \mathrm{~s}^{-1}$ with a $12 \mathrm{~h}$ light/12 h dark photoperiod; Christa et al. 2017). The intertidal $B$. corticulans was not specifically investigated in the work of Christa et al. (2017), where they found lower $F_{\mathrm{v}} / F_{\mathrm{m}}$ values $(\sim 0.62)$ when some of those species were grown under higher light intensity (i.e. $200 \mu \mathrm{mol}$ photons $\mathrm{m}^{-2}$ $\mathrm{s}^{-1}$ ), due to absence of a full recovery of sustained NPQ components.

Bryopsis corticulans siphonous morphology consists of branched thalli that form free-floating, intensely green tufts of filaments (Graham and Wilcox 2000). Such filaments are interconnected and thickly amassed, especially when fully exposed to the atmosphere (Fig. 1a). The absorption spectra measured on single thin layers of filaments (with filament diameter of $0.26 \pm 0.02 \mathrm{~mm}$ ) showed a high, maximal optical density (OD) of $0.62 \pm 0.03$ in the $\mathrm{Q}_{\mathrm{y}}$ region of Chl $a$ and a significant contribution of $\mathrm{Chl} b$ (at $\sim 650 \mathrm{~nm}$; Fig. 1b). It should be noted that $\mathrm{OD} \sim 0.6$ corresponds to a reduction in incident light intensity of $\sim 75 \%$ (Ruban 2012). The high $\mathrm{Chl} b$ content is in line with previous spectroscopic and biochemical studies on LHCII from B. corticulans (Chen et al. 2005, 2008; Wang et al. 2013) and the particularly low Chl $a / b$ ratio $(1.26 \pm 0.03)$ of chloroplasts isolated in this study. These results indicate the presence of a large lightharvesting antenna efficiently adapted to shaded conditions (Anderson and Osmond 1987; Anderson et al. 1988), rather than the high light experienced during emersions.

The relative electron transport rates (ETR), assessed on dark-adapted algal tufts in the field through rapid light curves (RLC; Platt et al. 1980), support the shade adaptation of this macroalga (Fig. 2). With a substantially lower saturation light of photosynthesis $\left(\mathrm{Ek} \sim 130 \mu \mathrm{mol}\right.$ photons $\mathrm{m}^{-2}$ 
$\mathrm{s}^{-1}$ ) than the high light intensities endured during emersion, maximum ETR was $28.4 \pm 1.07 \mu \mathrm{mol}$ electrons $\mathrm{m}^{-2} \mathrm{~s}^{-1}$ and saturated at $\sim 400 \mu \mathrm{mol}$ photons $\mathrm{m}^{-2} \mathrm{~s}^{-1}$, after which loss of PSII function was observed (Giovagnetti and Ruban 2015) (Fig. 2). RLC-retrieved parameters here presented are in agreement with other reports on intertidal green macroalgae during low tides (e.g. Gómez et al. 2004; Wang et al. 2012; Holzinger et al. 2015).

\section{Roles played by the algal body morphology of $B$. corticulans in photoprotection}

Given the morphology and absorption properties of the filament clusters of $B$. corticulans, we investigated if the 'algal body architecture' could itself function in the photoprotective strategy adopted against excess light exposure. Laboratory experiments were thus designed to investigate how the canopy effect produced by the siphonous morphology modulates NPQ induction and relaxation, and photochemical quenching $\left(\mathrm{q}_{\mathrm{P}}\right)$.

Freshly collected, whole algal tufts were dark adapted and placed in a small beaker, submerged in filtered seawater. Chl fluorescence quenching was measured either on 'surface filaments' exposed to the air, or 'bottom filaments' that were $2 \mathrm{~cm}$ underwater below the algal surface layer (see Fig. 3a and refer to "Materials and methods" for the experimental setup). While the surface filaments of the algal thallus were illuminated by high actinic light intensity (2000 $\mu \mathrm{mol}$ photons $\mathrm{m}^{-2} \mathrm{~s}^{-1}$, for $1 \mathrm{~h}$ ), the same light intensity on the bottom filaments was strongly attenuated as a result of the absorption of the overlying filaments floating in the water (Figs. 1b, 3a). The experimental setup prevented

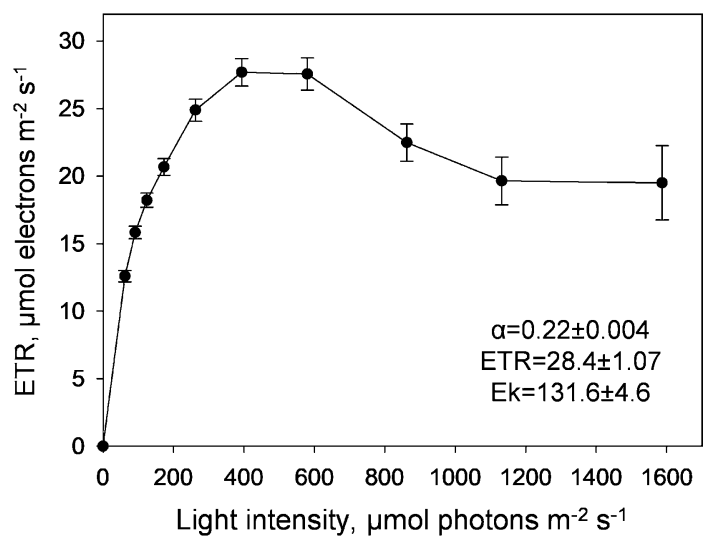

Fig. 2 Rapid light curves measured on freshly collected B. corticulans algal tufts. Algae were dark adapted for $30 \mathrm{~min}$, after which ten gradually increasing intensities of actinic light were applied, each lasting $10 \mathrm{~s}$ and followed by a saturating pulse. Data are averages of 24 repeats \pm SEM. Relative photosynthetic efficiency $(\alpha)$, electron transport rate (ETR) and light-saturation parameter (Ek) were calculated by fitting the model of Platt et al. (1980) accurate measurements of the light attenuation. However, it should be noted that if evenly absorbing filaments were closely attached, the light intensity would have exponentially decreased to zero in less than ten filaments (given an $\mathrm{OD} \sim 0.6$ per single filament of $\sim 0.25 \mathrm{~mm}$ diameter; Fig. 1b).

As predicted, we found a strong quenching at the surface layer of filaments (Fig. 3b), but almost none in the filaments underneath (Fig. 3c). NPQ induction was barely visible in the bottom filaments (Fig. 3d), and while the occurrence of state transitions cannot be ruled out (Fig. 3c), qT was not investigated in the present work. In contrast, at the surface, NPQ gradually formed over $1 \mathrm{~h}$ of illumination, reaching very high levels $(6.1 \pm 0.3$, Fig. $3 \mathrm{~d})$. Moreover, $F_{\mathrm{o}}$ quenching occurred, indicating the presence of an antenna-associated NPQ (Horton and Ruban 1993) in B. corticulans, as it is currently, widely accepted for higher plants and other photosynthetic organisms (Ruban et al. 2012; Goss and Lepetit 2015). However, NPQ was sustained, almost without any recovery during prolonged darkness (Fig. 3d), and its formation was not related to XC activity, since zeaxanthin was not detected in chloroplasts (Table 1; different light intensities were used to modulate the extent of NPQ). Only a minor and stable amount of violaxanthin was found together with several major carotenoids, including the typical $\mathrm{Sx}$ and $\mathrm{S}$ (Table 1) (Chen et al. 2008; Wang et al. 2013; Qin et al. $2015 b)$. Both results agree with a recent study revealing the absence of the fast and reversible $\mathrm{qE}$ component in Bryopsidales, where NPQ was found to be $\Delta \mathrm{pH}$ independent and not related to XC (Christa et al. 2017).

In relation to the clear diversity in NPQ kinetics observed, $q_{\mathrm{P}}$ significantly differed between surface and bottom filaments during illumination $(P<0.05$, Fig. 3e). In the surface filaments, a rapid drop in $q_{\mathrm{P}}$ was initially seen as the actinic light was switched on, followed by a gradual increase during most of the remaining illumination period. This suggests that NPQ formation released the excitation pressure in the antenna, until the last 10 min of illumination, when $q_{\mathrm{P}}$ decreased again $\left(q_{\mathrm{P}} \sim 0.2\right.$, Fig. 3e). Surprisingly, while the first average $q_{\mathrm{Pd}}$ values (taken after $10 \mathrm{~s}$ of darkness) were significantly different between the two conditions $\left(q_{\mathrm{Pd}} \sim 0.6\right.$ and $\sim 0.86$ in surface and bottom filaments, respectively; $P<0.05)$, no significant difference was found in $q_{\text {Pd }}$ between the two layers during the first $80 \mathrm{~min}$ of recovery in the dark $\left(P>0.05\right.$, Fig. 3e). Moreover, $q_{\mathrm{Pd}}$ recovered to 1.00 in $\sim 40 \mathrm{~min}$ (Fig. 4b), which is a much faster kinetics than that observed in A. thaliana leaves (Ruban and Belgio 2014). Although the NPQ process could not fully prevent photodamage in filaments exposed to high light, the loss of PSII function was quickly recovered in the dark, regardless of the lack of NPQ fast reversibility (Fig. 3d). This underlines the protective effectiveness of the antenna-based, sustained NPQ that was activated in filaments exposed to high light. 


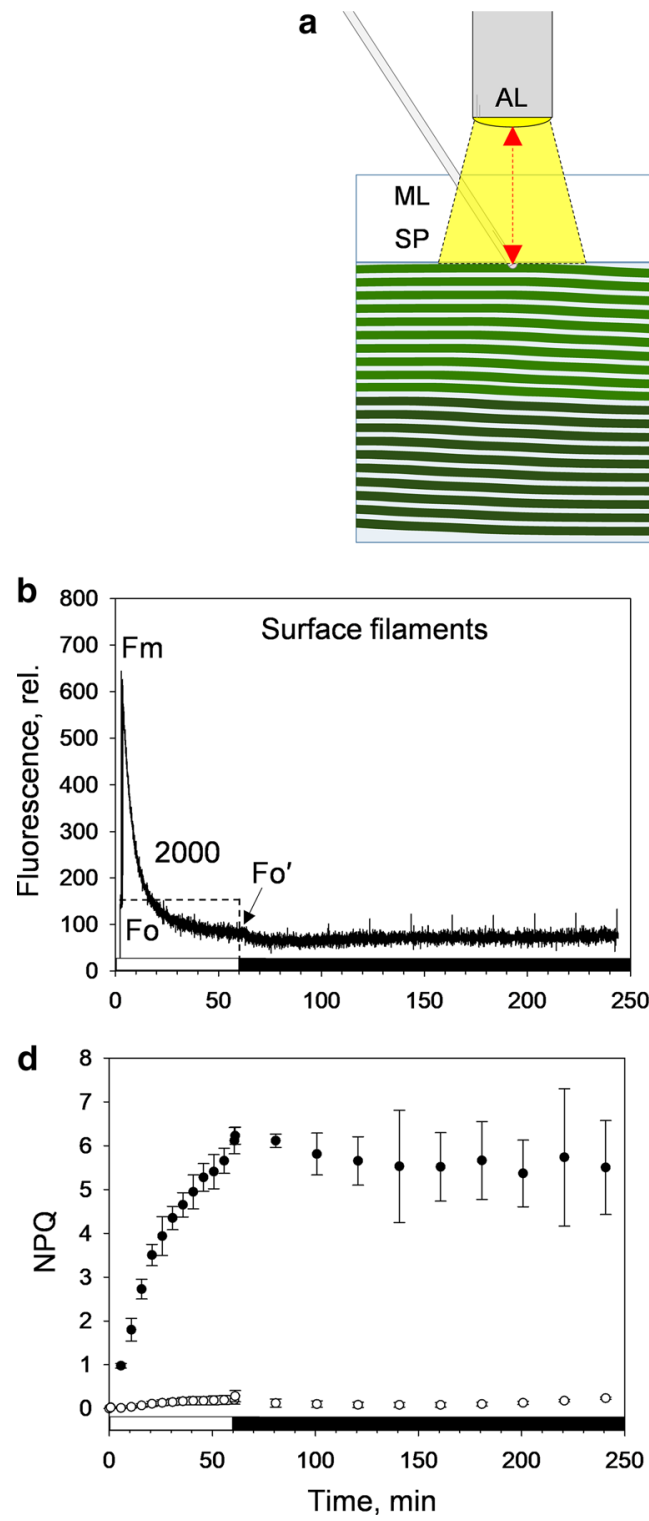

Fig. 3 Diagram of the experimental setup used in the laboratory (a) to assess chlorophyll fluorescence induction and relaxation in surface and bottom filaments of $B$. corticulans $(\mathbf{b}, \mathbf{c})$. Representative traces are shown for surface (air exposed, b) and bottom filaments $(2 \mathrm{~cm}$ underneath the surface layer and underwater, c). Evolution of nonphotochemical fluorescence quenching (NPQ, d) and photochemical fluorescence quenching over time $\left(q_{\mathrm{P}}\right.$ and $q_{\mathrm{Pd}}, \mathbf{e}$; see Ruban and Murchie 2012). Closed and open circles represent surface and bottom filaments, respectively (d, e). Filaments were illuminated by two external light probes, with white actinic light (AL) intensity of $2000 \mu \mathrm{mol}$

From $140 \mathrm{~min}$ (i.e. after $80 \mathrm{~min}$ in the dark), $q_{\mathrm{Pd}}$ values became again significantly different between the two conditions $(P<0.05)$, potentially because of the occurrence of some antenna detachment in the surface filaments, as indicated by the slight rise in $q_{\mathrm{Pd}}$ above 1.00 (Fig. 3e; see Giovagnetti and Ruban 2015; Ware et al. 2015). However, we are not able to explain the decrease in $q_{\mathrm{Pd}}$ below 0.98
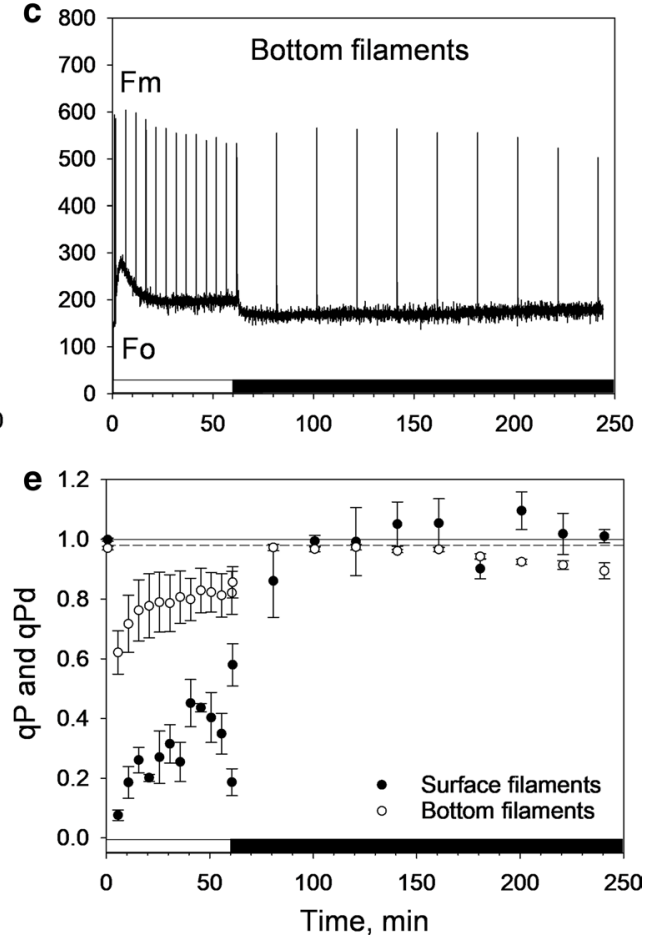

photons $\mathrm{m}^{-2} \mathrm{~s}^{-1}$. Measuring light (ML) and saturating light pulses (SP, $0.6 \mathrm{~s}$ and $4000 \mu \mathrm{mol}$ photons $\mathrm{m}^{-2} \mathrm{~s}^{-1}$ ) were provided by two JUNIOR-PAM fibre optics, which were secured to prevent movement. $1 \mathrm{~h}$ of AL illumination (white bars) was followed by $3 \mathrm{~h}$ of recovery in the dark (black bars). An SP was applied every 5 min during light treatment, and $10 \mathrm{~s}$ after the actinic light was switched off, as well as every $20 \mathrm{~min}$ in the dark. For both layers, four independent measurements were performed. Averages are four repeats \pm SEM. $F_{m}$ maximum fluorescence in the dark, and $F_{o}$ and $F_{o}{ }^{\prime}$ minimum fluorescence in the dark and after AL exposure, respectively

measured in the bottom filaments, which is unrelated to photodamage, since samples were already in the dark for $2 \mathrm{~h}$ and PSII functionality was not impaired after the light treatment (Fig. 3e). A possible rearrangement of antenna pigment-protein complexes in these shaded filaments might have affected $q_{\mathrm{Pd}}$ during prolonged darkness. 
Table 1 Carotenoid content of B. corticulans chloroplasts

\begin{tabular}{lllllc}
\hline Light conditions & Sx/Car & S/Car & Sx/S & Vx/Car & NPQ \\
\hline Dark & $0.209 \pm 0.001$ & $0.174 \pm 0.001$ & $1.200 \pm 0.002$ & $0.054 \pm 0.0003$ & $0.0 \pm 0.0$ \\
Low light & $0.212 \pm 0.001$ & $0.175 \pm 0.001$ & $1.212 \pm 0.003$ & $0.054 \pm 0.0002$ & $0.2 \pm 0.02$ \\
Moderate light & $0.224 \pm 0.001$ & $0.179 \pm 0.001$ & $1.250 \pm 0.005$ & $0.053 \pm 0.001$ & $1.01 \pm 0.01$ \\
High light & $0.240 \pm 0.009$ & $0.190 \pm 0.008$ & $1.264 \pm 0.005$ & $0.055 \pm 0.001$ & $2.01 \pm 0.01$ \\
\hline
\end{tabular}

Chloroplasts were either dark adapted or exposed to low $\left(211 \mu \mathrm{mol}\right.$ photons $\left.\mathrm{m}^{-2} \mathrm{~s}^{-1}, 5 \mathrm{~min}\right)$, moderate (760 $\mu \mathrm{mol}$ photons $\left.\mathrm{m}^{-2} \mathrm{~s}^{-1}, 30 \mathrm{~min}\right)$ and high light intensity $\left(2500 \mu \mathrm{mol}\right.$ photons $\left.\mathrm{m}^{-2} \mathrm{~s}^{-1}, 30 \mathrm{~min}\right)$ to induce non-photochemical quenching (NPQ). The corresponding NPQ values are shown in the table. Carotenoid changes are presented as the ratio between relative integrated peak areas of HPLC chromatograms. Data are mean \pm SEM of three repeats

Car total carotenoid content (siphonaxanthin, all-trans neoxanthin, 9'-cis neoxanthin, violaxanthin, siphonein, $\varepsilon$-carotene and $\alpha$-carotene), $S$ siphonein, $S x$ siphonaxanthin, $V x$ violaxanthin
Overall, we reveal the key role played by the siphonous morphology in light-harvesting regulation and adaptation to the intertidal light environment in B. corticulans, based on the presence of a slowly reversible, protective NPQ, which does not relate to photodamage.

\section{Functional insights into the NPQ mechanism of $B$. corticulans}

The sustained NPQ in other species belonging to the same order as B. corticulans has been proposed not to be triggered by the thylakoid lumen acidification (Christa et al. 2017). To see if this also holds for B. corticulans, chloroplasts were isolated and the $\mathrm{Chl}$ fluorescence kinetics in nigericinand DAD-treated samples were monitored and compared to control untreated ones (Fig. 4). The uncoupler nigericin was used to collapse the $\Delta \mathrm{pH}$ across thylakoid membrane, whereas DAD increased the levels of $\Delta \mathrm{pH}$ by stimulating cyclic electron flow around PSI. Both molecules are widely used and known to alter qE (Wraight and Crofts 1970; Johnson and Ruban 2011).

Figure 4 depicts representative fluorescence traces from intact chloroplasts $\left(F_{\mathrm{v}} / F_{\mathrm{m}} \sim 0.73\right)$ in response to $5 \mathrm{~min}$ illumination followed by 5 min in the dark. Disruption (nigericin, Fig. 4b) or enhancement (DAD, Fig. 4c) of the transmembrane proton gradient controlled the extent of quenching accordingly. After light treatment, NPQ was $\sim 4$ times higher when chloroplasts were treated with DAD, in comparison to the control, while nigericin prevented NPQ formation (Fig. 5a). The low NPQ levels measured were related to the low actinic light and short treatment applied (i.e. $211 \mu \mathrm{mol}$ photons $\mathrm{m}^{-2} \mathrm{~s}^{-1}$ for $5 \mathrm{~min}$ ). Larger NPQ values were indeed achieved under greater light intensities and longer treatment ( $30 \mathrm{~min}$, Fig. 6; Table 1). Regardless of the low actinic light, NPQ was not able to relax during darkness in control and DAD-treated samples (Fig. 5a), but it rather increased, in agreement with the sustained nature of the NPQ revealed in vivo in this study (Fig. 3b, d) and in Bryopsidales (and Christa et al. 2017). When nigericin was added, NPQ was just measurable, but exhibited a similar, slight increase during dark relaxation as in control and DAD conditions (Fig. 5a). Thus, NPQ is triggered by the initial lumen acidification in B. corticulans chloroplasts, which possibly initiates a reorganisation of the antenna (Ruban et al. 2012) that does not reverse quickly in the dark. This fits with the alga adaptation to prolonged emersions. Moreover, the larger the NPQ, the lower is the excitation pressure of the antenna, resulting in the fastest and highest $q_{\mathrm{Pd}}$ recovery in DAD-treated chloroplasts after $5 \mathrm{~min}$ of dark recovery $(0.96 \pm 0.02$, Fig. $5 b) . q_{\mathrm{Pd}}$ recovery was instead comparable between control and nigericin treatment (Fig. 5b). The fact that enhancing NPQ clearly reduced photodamage of chloroplasts further proves the protective nature of the sustained NPQ formed by B. corticulans.

Specific proteins control $\mathrm{qE}$ in higher plants (PsbS) and other green algae (e.g. PsbS and LHCSR in C. reinhardtii) (Bonente et al. 2011; Ruban 2016; Tibiletti et al. 2016). However, the presence of PsbS and LHCSR is yet to be confirmed in Bryopsidales (Handrich et al. 2017), possibly in line with the reported lack of a flexible $\mathrm{qE}$ (Christa et al. 2017). Since biochemical studies are clearly needed to exclude their occurrence (Handrich et al. 2017), we performed western blotting employing anti-PsbS and anti-LHCSR3/1 antibodies. B. corticulans chloroplasts were either dark adapted, illuminated $(\mathrm{NPQ}=2.3 \pm 0.25)$ or dark adapted for $1 \mathrm{~h}$ after illumination (recovery $\mathrm{NPQ}=1.9 \pm 0.23$; Fig. 7). Dark-adapted chloroplasts of $S$. oleracea and C. reinhardtii were used as controls (Fig. 7).

Monomers of PsbS $(\sim 20 \mathrm{kDa})$ were only found in S. oleracea (PsbS, Fig. 7a), whereas monomers of LHCSR3 and LHCSR1 ( $26 \mathrm{kDa})$ were found in $C$. reinhardtii (Fig. 7b, c). The presence of both LHCSR isoforms in C. reinhardtii samples was achieved by growing the algae under high light. Bands suggesting the presence of PsbS dimers ( 40 kDa) and LHCSR3/LHCSR1 oligomers (MW $42 \mathrm{kDa}$, potentially LHCSR dimers) were also visible in $S$. oleracea and $C$. reinhardtii, respectively (Fig. 7). Most relevantly, no monomer of either of the proteins was detected in B. corticulans 

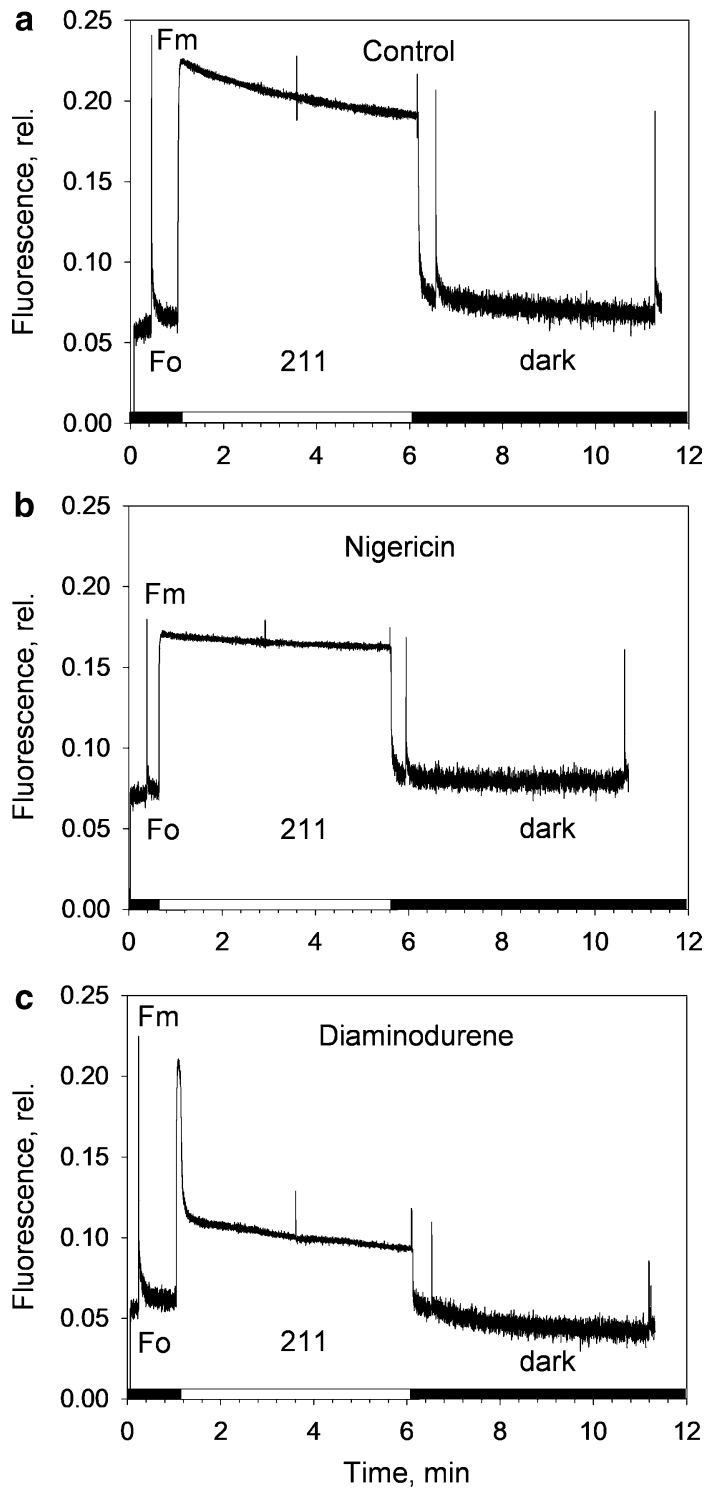

Fig. 4 Representative traces of chlorophyll fluorescence induction and relaxation from $B$. corticulans chloroplasts. Measurements were carried out on $2 \mathrm{ml}$ of intact chloroplasts (final concentration of $35 \mu \mathrm{M}$ of $\mathrm{Chl}$ in resuspension buffer) in a quartz cuvette. Constant, gentle stirring was applied. Actinic light intensity was $211 \mu \mathrm{mol}$ photons $\mathrm{m}^{-2} \mathrm{~s}^{-1} .100 \mu \mathrm{M}$ nigericin or $600 \mu \mathrm{M}$ diaminodurene was added in the dark to prevent or enhance the formation of $\Delta \mathrm{pH}$ across the thylakoid membrane, respectively. Illumination treatment lasted for $5 \mathrm{~min}$, followed by $5 \mathrm{~min}$ in the dark. An SP was applied after 2 and $5 \mathrm{~min}$ during light treatment, and after $10 \mathrm{~s}$ and $5 \mathrm{~min}$ in the dark. Three to four independent measurements were performed. $F_{m}$ maximum fluorescence in the dark, $F_{o}$ minimum fluorescence in the dark

(Fig. 7), but only their dimeric or oligomeric states, regardless of light/dark treatment (Fig. 7). This was not altered when denaturing samples at room temperature, instead of heating them at $40{ }^{\circ} \mathrm{C}$ for $10 \mathrm{~min}$. Bands corresponding to PsbS dimers have been already shown in higher plants despite the use of denaturing SDS-PAGE (Bergantino et al.
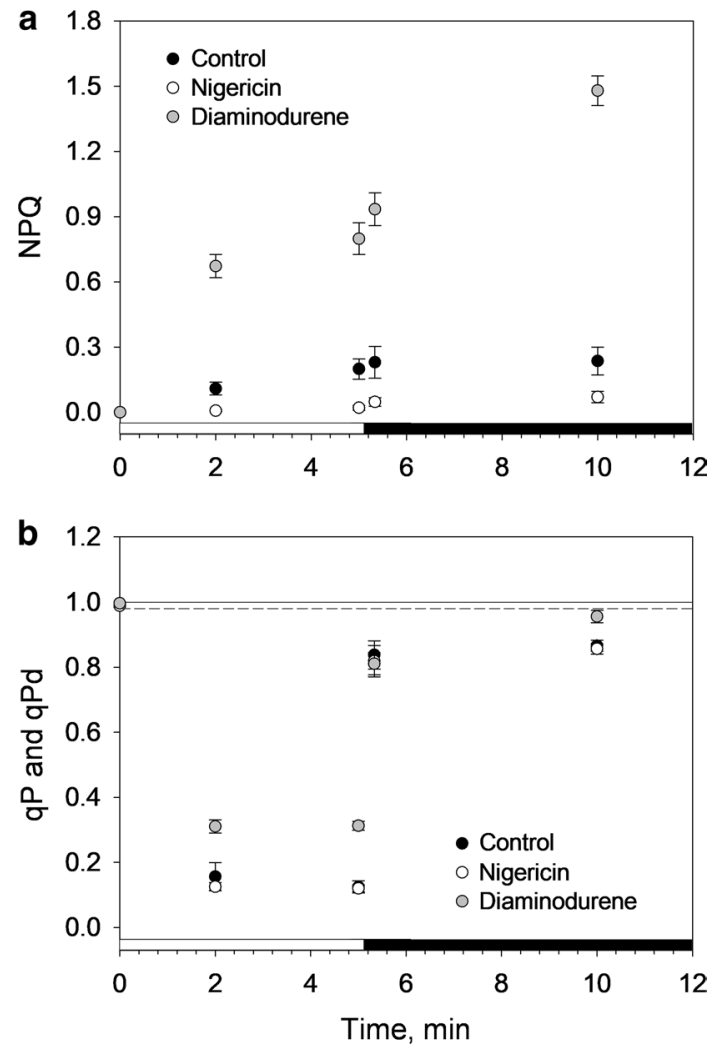

Fig. 5 Evolution of non-photochemical fluorescence quenching (NPQ, a) and photochemical fluorescence quenching over time $\left(q_{\mathrm{P}}\right.$ and $q_{\mathrm{Pd}}$, b) on B. corticulans chloroplasts. Control (black circles), nigericin- (white circles) and diaminodurene (DAD)-treated samples (grey circles) were illuminated with an actinic light intensity of $211 \mu \mathrm{mol}$ photons $\mathrm{m}^{-2} \mathrm{~s}^{-1}$ for $5 \mathrm{~min}$. Recovery in the dark lasted $5 \mathrm{~min}$. Averages are three to four repeats \pm SEM

2003; Sacharz et al. 2017), while LHCSR dimer formation has been seen in $C$. reinhardtii by native electrophoresis (Bonente et al. 2011). At the same time, caution should be taken when using antibodies whose reactivity has been only confirmed in other model species. For this reason, unspecific binding of antibodies cannot be fully excluded at this stage.

\section{Discussion}

Life in the intertidal ecosystems demands a precise regulation of photosynthesis to adapt to the rapidly changing light environment. For intertidal algae, the timing of atmosphere or water exposure interacts with diel extreme changes in light and other essential abiotic factors (Madsen and Maberly 1990; Davison and Pearson 1996; Hurd et al. 2014). Nonetheless, high diversity and density of algae are often found in intertidal rocky habitats, implying they evolved a flexible, robust photosynthetic machinery capable of withstanding such abiotic challenges. 

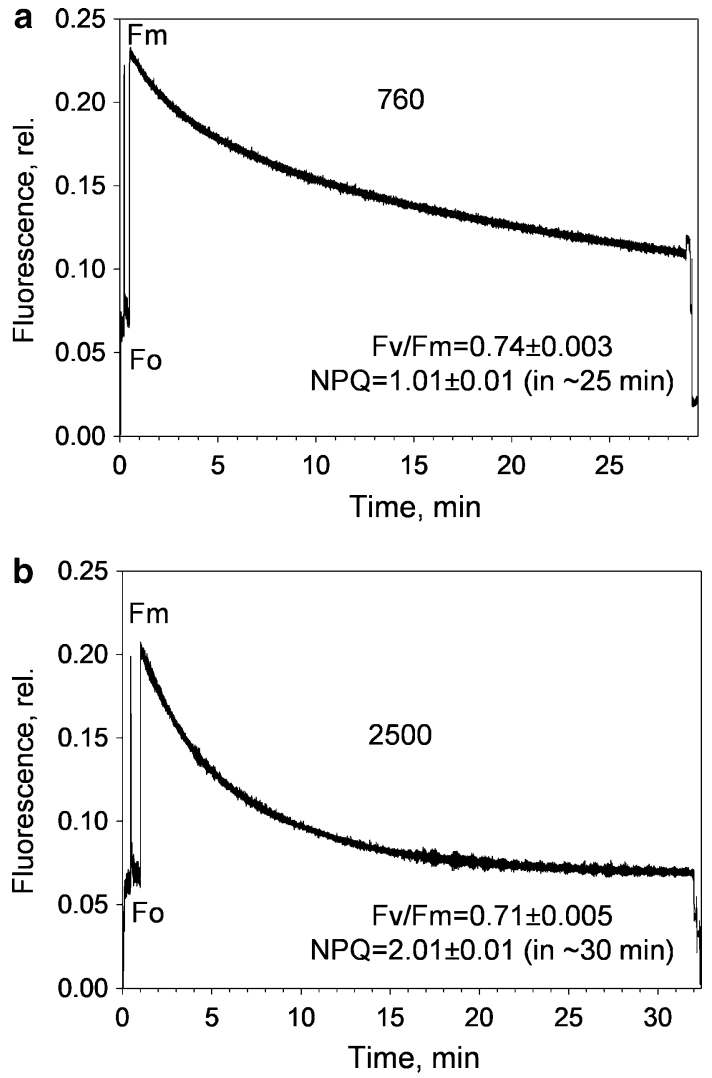

Fig. 6 Representative traces of chlorophyll fluorescence induction from B. corticulans chloroplasts. Measurements were carried out on $2 \mathrm{~mL}$ of intact chloroplasts (final concentration of $35 \mu \mathrm{M}$ of $\mathrm{Chl}$ in resuspension buffer) in a quartz cuvette. Constant, gentle stirring was applied. High actinic light intensities (760 and $2500 \mu \mathrm{mol}$ photons $\mathrm{m}^{-2} \mathrm{~s}^{-1}, 30 \mathrm{~min}$ ) were used to induce high NPQ. Three to four independent measurements were performed, and the corresponding $F_{\mathrm{v}} / F_{\mathrm{m}}$ and NPQ data are averages of the three to four repeats \pm SEM

We studied the siphonous green macroalga, B. corticulans, which belongs to the cosmopolitan order of Bryopsidales, ecologically relevant for being major primary producers in tropical marine habitats and notorious invasive species (e.g. Codium fragile and Caulerpa taxifolia) (Graham and Wilcox 2000; Provan et al. 2004; Verbruggen et al. 2009). In particular, we address the regulation of light harvesting and photoprotection when $B$. corticulans tufts, formed by multiple filaments, experience high light stress during low tides.

Our data show that $B$. corticulans possesses a large lightharvesting antenna and is a shade-adapted species (Anderson and Osmond 1987; Anderson et al. 1988), in agreement with observations made in other marine green macroalgae (Anderson et al. 1980; Anderson 1983; Yamazaki et al. 2005). The $\mathrm{Chl} a / b$ ratios here measured in chloroplasts $(\sim 1.26)$ are substantially lower than those of thylakoid membranes of shade-adapted (2.0-2.2) and light-adapted plants (2.6-3.6) (Anderson et al. 1988; Ware et al. 2015). The a

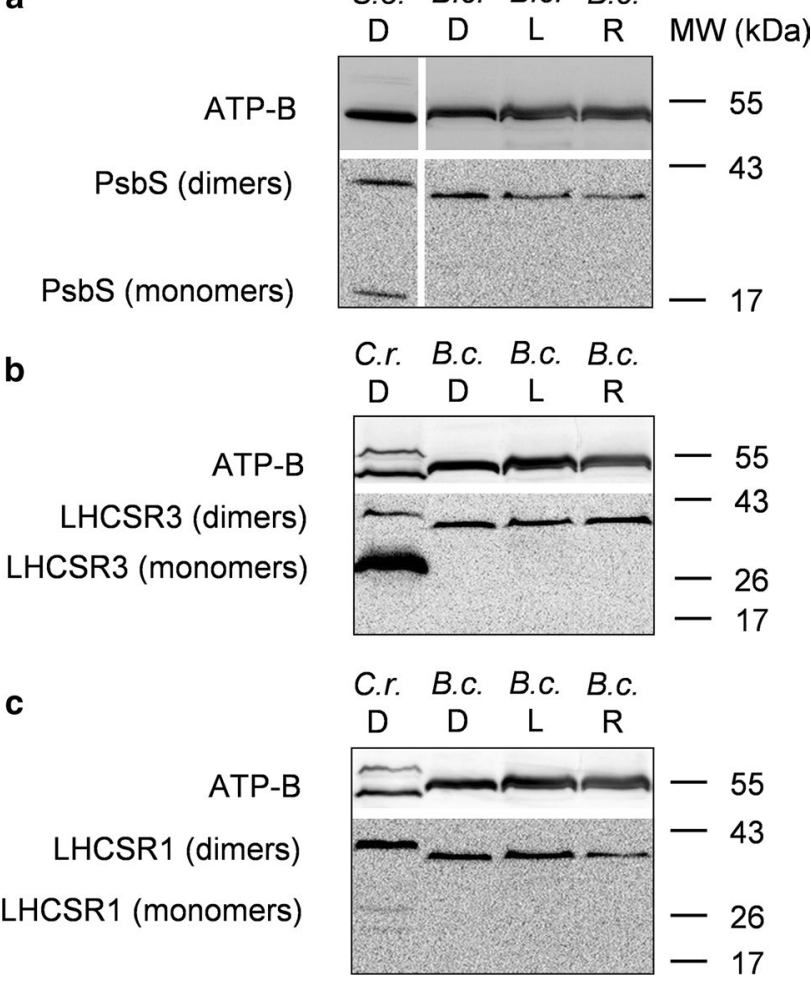

Fig. 7 Western blot analysis of PsbS and LHCSR proteins from darkadapted (D, $30 \mathrm{~min}$ ), light-treated (L, $2500 \mu \mathrm{mol}$ photons $\mathrm{m}^{-2} \mathrm{~s}^{-1}$, $30 \mathrm{~min})$ and post-dark-recovery chloroplasts (R, $1 \mathrm{~h})$ isolated from $B$. corticulans. Samples were analysed by immunoblotting with an antiPsbS (a), anti-LHCSR3 (b) and anti-LHCSR1 antibodies (c). Control samples are dark-adapted $S$. oleracea (a) and C. reinhardtii chloroplasts $(\mathbf{b}, \mathbf{c})$. Note that $B$. corticulans and $S$. oleracea samples have been probed against anti-PsbS antibody in the same membrane. The separation between lanes is only due to the presence of different samples between those presented of $S$. oleracea and B. corticulans (a). The $\beta$ subunit of ATP synthase (ATP-B) was used as loading control. $10 \mu \mathrm{g}$ of $\mathrm{Chl}$ was loaded in each lane

presence of such a large antenna is also consistent with the measured $F_{\mathrm{v}} / F_{\mathrm{m}}$ values, lower than those reported in plants. When submerged in turbid, intertidal waters, $B$. corticulans algae grow and fix inorganic carbon under low light, where the reflection at the water surface and absorption/scattering by particles dissolved or suspended in the water affect the light quality available (Kirk 2011). In these conditions, not only the size, but also the pigment composition of $B$. corticulans antenna complexes provides an ecological advantage. Being equipped with the class-specific carotenoids, Sx and S (Nakayama and Okada 1990; Chen et al. 2005, 2008; Wang et al. 2013), B. corticulans can indeed exploit the spectral region of blue-green light (Kirk 2011).

Given this enhanced capacity to absorb a limiting amount of photons underwater, high light must be in turn safely dissipated during complete or partial exposure to air, as light becomes oversaturating. In these conditions, $B$. corticulans 
is able to efficiently cope with excess light energy absorption by adopting a 'locked' sustained protective state of the lightharvesting systems in filaments that are directly subjected to excess light. A very high NPQ is measured in these surface filaments, which forms gradually and is independent of XC operation (here and Wang et al. 2013). The morphology of B. corticulans thallus, coupled with the optical properties of its filaments, creates a marked canopy effect on layers that are not directly hit by sunrays. The consequent filament self-shading and light screening cause a very effective functional segregation between algal filaments that switch into a prolonged dissipative state, and those underneath, which can maximise the capture of the attenuated light to ensure efficient photosynthesis. We can assume that such a separation gradually builds within the algal tufts in their natural habitat, and the extent and recovery of the observed sustained NPQ change. This explains why high $F_{\mathrm{v}} / F_{\mathrm{m}}$ values can be measured in the field after 30 min dark adaptation. In this context, it should also be noted that the in situ experiments took place during a window of hours in which the tidal level and light intensity varied over time. This 'natural scenario' clearly imposes a more variable excitation pressure on the algal filaments when compared with the controlled, extreme illumination provided in the laboratory (i.e. constant and prolonged, high illumination applied on filaments that were statically floating in a beaker). On one side, this is consistent with the average $F_{\mathrm{v}} / F_{\mathrm{m}}(\sim 0.76)$ and its variability observed (range between $\sim 0.69$ and $\sim 0.8$ ) in the field, and on the other side with the lack of NPQ relaxation in the surface layers probed in the laboratory. Differently, when fluorescence changes are probed in the filaments $2 \mathrm{~cm}$ below the illuminated surface layer, almost no NPQ occurs. This means that, although the activation of sustained NPQ undermines photochemistry in the surface filaments, the inner layers of the algal thallus can maintain efficient photosynthetic rates. Furthermore, PSII yield in the surface filaments was $\sim 0.4$ during dark recovery $\left(F_{\mathrm{v}}{ }^{\prime \prime} / F_{\mathrm{m}}{ }^{\prime \prime}\right)$, thus assuring $\sim 40 \%$ efficiency of light energy use upon a subsequent submersion.

The presence of PsbS and LHCSR is debated in Bryopsidales (Christa et al. 2017; Handrich et al. 2017). No transcripts of PsbS and LHCSR have been found from transcriptomic analysis conducted on Bryopsis hypnoides and $C$. taxifolia (Handrich et al. 2017). Nonetheless, the expression of PsbS and LHCSR was reported and shown to be regulated by light changes in Ulva linza (Zhang et al. 2012) and Ulva prolifera (Mou et al. 2013). Although PsbS and LHCSR function is currently unknown in these species, these data indicate their possible involvement in the NPQ modulation in some Ulvophyceae. The presence of both proteins was therefore addressed in the present study, showing no lightinduced transient monomerisation of PsbS and LHCSR3/ LHCSR1 proteins in B. corticulans. Assuming a specific binding of the antibodies used, both types of proteins were detected as dimers or oligomers in B. corticulans, thus capable of withstanding solubilisation by SDS/LDS (see Bergantino et al. 2003). At the same time, primary antibody crossreactivity to different protein sequences cannot be ruled out in B. corticulans. Hence, data interpretation must be careful.

The role played by monomeric and dimeric forms of PsbS and LHCSR proteins in NPQ is controversial. In plants, dimeric and monomeric PsbS has been found associated to LHCs in the thylakoid membrane, with dimers prevalently abundant at alkaline $\mathrm{pH}$ and monomers at acidic $\mathrm{pH}$ (Bergantino et al. 2003; Sacharz et al. 2017). Thus, it has been proposed that the PsbS dimer-to-monomer conversion is reversibly triggered by light and the presence of PsbS monomers is linked to NPQ formation (Bergantino et al. 2003; Sacharz et al. 2017). Nonetheless, PsbS homodimers have also been reported in the NPQ state of the antenna (Fan et al. 2015). Although LHCSR monomers have been usually reported during NPQ formation in $C$. reinhardtii and P. patens (e.g. Bonente et al. 2011; Pinnola et al. 2013), it has been recently speculated that finding LHCSR dimers in thylakoid membranes indicates the need for LHCSR3 activity of specific protein-protein interactions (Ballottari et al. 2016). However, no direct evidence for the photoprotective role of LHCSR dimers has been provided so far.

Given our results, as well as the sustained nature of NPQ observed, we propose that PsbS and LHCSR are not active in the NPQ mechanism of B. corticulans. Possibly, this is because they are either not functional (i.e. present as dimers or oligomers) or absent. The lack of the activity of allosteric regulators, such as XC and PsbS/LHCSR proteins, agrees with the absence of a fast and reversible $\mathrm{qE}$ in this species, as revealed here both in vivo and in isolated chloroplasts. This is consistent with a recent study on photoprotection of several Bryopsidales species (Christa et al. 2017). Although a 'classical qE component', characterised by fast development and reversibility, is missing in B. corticulans, we demonstrate that the transmembrane proton gradient is needed to initiate NPQ. Indeed, the absence of lumen acidification blocks NPQ induction in chloroplasts. Interestingly, our results find support from NPQ data collected on B. hypnoides, i.e. another intertidal macroalga that belongs to the same genus of the species here studied (Christa et al. 2017). A significant decrease in NPQ capacity is found when this alga is grown under low light and treated with nigericin (Christa et al. 2017). Differently, there is no obvious decrease in NPQ when it is cultured under high light, although the NPQ values measured are particularly low $(\sim 4$ times less than those measured in low light-adapted algae). We believe that this might have hidden the potential impact of proton gradient disruption on NPQ formation in B. hypnoides (Christa et al. 2017).

$\Delta \mathrm{pH}$ acts as a feedback signal linked to the degree of saturation of photosynthetic electron transport during light 
changes and controls induction and relaxation of the fast qE (Cardol et al. 2011; Ruban et al. 2012). Differently, in $B$. corticulans, lumen acidification seems to trigger only NPQ induction, which becomes persistent once activated. We hypothesise that antenna rearrangement (and possibly some uncoupling, suggested by the $q_{\mathrm{Pd}}$ rise) is involved in this sustained NPQ, which fits this species adaptation to the prolonged high light encountered during low tides. Measuring potential variations in PSII antenna cross section, and investigating structural and dynamic changes that underlie NPQ kinetics (e.g. freeze-fracture electron microscopy), could further unveil how the light-harvesting system of B. corticulans locks in into a long-term protective conformation.

Particularly outstanding is finding that the observed sustained NPQ, unrelated to violaxanthin de-epoxidation, is particularly effective in limiting the impairment/loss of PSII function, which is reflected as a decline in $q_{\text {Pd }}$ below 0.98 (Ruban and Murchie 2012). Indeed, despite 40\% of RCs in the surface filaments is photodamaged by the prolonged high light illumination $\left(q_{\mathrm{Pd}} \sim 0.6\right), \sim 100 \%$ of RCs become open and functional after 40 min of darkness ( $q=1.00$, see Fig. 3e), whilst the high NPQ formed does not recover. This indicates and further supports the fact that NPQ components that slowly relax, and are often referred as qI, can still protect PSII RCs against photodamage (Ruban and Murchie 2012; Giovagnetti and Ruban 2015; Ware et al. 2015). Moreover, we show that high NPQ levels can be reached without the involvement of zeaxanthin, possibly relying on light-harvesting antenna rearrangement that allows conformational changes affecting the pigment-pigment and pigment-protein interactions responsible for quenching (Ruban 2016). These results suggest that either some transient photoinactivation of PSII, which does not require dismantling and repairing of photodamaged RCs, takes place, or the rate of PSII repair cycle is particularly fast in B. corticulans. Although at the moment we cannot exclude any of these hypotheses, further studies are required to elucidate $B$. corticulans resilience to photodamage.

In conclusion, we report that $B$. corticulans is able to cope with excess light energy by activating sustained protective NPQ. The siphonous cytology and morphology, and the peculiar molecular mechanics of NPQ adopted, enable this intertidal macroalga to efficiently protect itself, while still performing photosynthesis in the inner body filaments.

Author contribution statement VG, GH, MAW, TK, J-RS and AVR planned and designed the research; VG, GH, MAW, PU, XQ and WW performed the experiments. All authors analysed and interpreted the data. VG and AVR wrote the manuscript with contributions and inputs from all authors.
Acknowledgements This work was supported by the Royal Society grant International Exchanges Scheme IE141041 to A.V.R. and NSFC International Exchanges Scheme 31511130065 to G.H. A.V.R. acknowledges the Royal Society for the Wolfson Research Merit Award. This work was partially supported by the Leverhulme Trust Grant RPG-2015-008 and BBSRC grant BB/L019027/1 awarded to A.V.R, and a Key Research Project for Frontier Science No. QYZDYSSW-SMC003 from CAS, China. Alexandra Townsend is acknowledged for providing comments on the manuscript. We thank the editor and reviewers for the comments made on the manuscript.

Open Access This article is distributed under the terms of the Creative Commons Attribution 4.0 International License (http://creativeco mmons.org/licenses/by/4.0/), which permits unrestricted use, distribution, and reproduction in any medium, provided you give appropriate credit to the original author(s) and the source, provide a link to the Creative Commons license, and indicate if changes were made.

\section{References}

Alboresi A, Gerotto C, Giacometti GM, Bassi R, Morosinotto T (2010) Physcomitrella patens mutants affected on heat dissipation clarify the evolution of photoprotection mechanisms upon land colonization. Proc Natl Acad Sci USA 107:11128-11133

Amunts A, Drory O, Nelson N (2007) The structure of a plant photosystem I supercomplex at $3.4 \AA$ resolution. Nature 447:58-63

Anderson JM (1983) Chlorophyll-protein complexes of a Codium species, including a light-harvesting siphonaxanthin-chlorophyll $a / b$-protein complex, an evolutionary relic of some Chlorophyta. Biochim Biophys Acta 724:370-380

Anderson JM, Osmond CB (1987) Shade-sun responses: compromises between acclimation and photoinhibition. In: Kyle DJ, Osmond $\mathrm{CB}$, Arntzen CJ (eds) Photoinhibition, topics in photosynthesis, vol 9. Elsevier, Amsterdam, pp 1-38

Anderson JM, Waldron JC, Thorne SW (1980) Chlorophyll-protein complexes of a marine green alga Caulerpa cactoides. Plant Sci Lett 17:149-157

Anderson JM, Chow WS, Goodchild DJ (1988) Thylakoid membrane organization in sun/shade acclimation. Aust J Plant Physiol 15:11-26

Aro EM, Virgin I, Andersson B (1993) Photoinhibition of photosystem II. Inactivation, protein damage and turnover. Biochim Biophys Acta 1143:113-134

Bailleul B, Rogato A, de Martino A, Coesel S, Cardol P, Bowler C, Falciatore A, Finazzi G (2010) An atypical member of the lightharvesting complex stress-related protein family modulates diatom responses to light. Proc Natl Acad Sci USA 107:18214-18219

Ballottari M, Girardon J, Dall'Osto L, Bassi R (2012) Evolution and functional properties of photosystem II light harvesting complexes in eukaryotes. Biochim Biophys Acta 1817:143-157

Ballottari M, Truong TB, De Re E, Erickson E, Stella GR, Fleming GR, Bassi R, Niyogi KK (2016) Identification of pH-sensing sites in the light harvesting complex stress-related 3 protein essential for triggering non-photochemical quenching in Chlamydomonas reinhardtii. J Biol Chem 291:7334-7346

Bergantino E, Segalla A, Brunetta A, Teardo E, Rigoni F, Giacometti GM, Szabò I (2003) Light- and pH-dependent structural changes in the PsbS subunit of photosystem II. Proc Natl Acad Sci USA 100:15265-15270

Blankenship RE (2014) Molecular mechanisms of photosynthesis, 2nd edn. Wiley-Blackwell, Oxford

Blankenship RE, Sadekar S, Raymond J (2007) The evolutionary transition from anoxygenic to oxygenic photosynthesis. In: Falkowski 
PG, Knoll AH (eds) Evolution of primary producers in the sea. Elsevier, Boston, pp 21-35

Bonente G, Ballottari M, Truong TB, Morosinotto T, Ahn TK, Fleming GR, Niyogi KK, Bassi R (2011) Analysis of LhcsR3, a protein essential for feedback de-excitation in the green alga Chlamydomonas reinhardtii. PLoS Biol 9:e1000577

Cardol P, Forti G, Finazzi G (2011) Regulation of electron transport in microalgae. Biochim Biophys Acta 1807:912-918

Chen H, Shen S, Liang Y, Leng J, Tang M, Gong Y (2005) Evidence for dissociation of chlorophyll $b$ from the main light-harvesting complex in the oligomerization state isolated from a marine alga, Bryopsis corticulans. Biochim Biophys Acta 1707:170-178

Chen GY, Niu XD, Chen XB, Li LB, Kuang TY, Li SQ (2008) Characterization of chlorophyll-protein complex isolated from a siphonaceous green alga, Bryopsis corticulans. Photosynth Res 96:75-81

Christa G, Cruz S, Jahns P, de Vries J, Cartaxana P, Esteves AC, Serôdio J, Gould SB (2017) Photoprotection in a monophyletic branch of chlorophyte algae is independent of energy-dependent quenching (qE). New Phytol 214:1132-1144

Collins FS, Holden I, Setchell WA (1899) Phycotheca boreali-americana. A collection of dried specimens of the algae of North America, vol fasc XII-XIII, nos. 551-650, Malden

Croce R, van Amerongen H (2014) Natural strategies for photosynthetic light harvesting. Nat Chem Biol 10:492-501

Cruz S, Calado R, Serôdio J, Jesus B, Cartaxana P (2014) Pigment profile in the photosynthetic sea slug Elysia viridis (Montagu, 1804). J Moll Stud 80:475-481

Davison IR, Pearson GA (1996) Stress tolerance in intertidal seaweeds. J Phycol 32:197-211

Demmig-Adams B, Garab G, Adams W III, Govindjee (2014) Nonphotochemical quenching and energy dissipation in plants, algae and cyanobacteria. Springer, New York

Dinc E, Tian L, Roy LM, Roth R, Goodenough U, Croce R (2016) LHCSR1 induces a fast and reversible $\mathrm{pH}$-dependent fluorescence quenching in LHCII in Chlamydomonas reinhardtii cells. Proc Natl Acad Sci USA 113:7673-7678

Falkowski PG, Raven JA (2007) Aquatic photosynthesis, 2nd edn. Princeton University Press, Princeton

Fan M, Li M, Liu Z, Cao P, Pan X, Zhang H, Zhao X, Zhang J, Chang W (2015) Crystal structures of the PsbS protein essential for photoprotection. Nat Struct Mol Biol 22:729-735

Franklin LA, Levavasseur G, Osmond CB, Henley WJ, Ramus J (1992) Two components of onset and recovery during photoinhibition of Ulva rotundata. Planta 186:399-408

Giovagnetti V, Ruban AV (2015) Discerning the effects of photoinhibition and photoprotection on the rate of oxygen evolution in Arabidopsis leaves. J Photochem Photobiol B 152:272-278

Gómez I, Huovinen P (2011) Morpho-functional patterns and zonation of South Chilean seaweeds: the importance of photosynthetic and bio-optical traits. Mar Ecol Prog Ser 422:77-91

Gómez I, López-Figueroa F, Ulloa N, Morales V, Lovengreen C, Huovinen P, Hess S (2004) Patterns of photosynthesis in 18 species of intertidal macroalgae from southern Chile. Mar Ecol Prog Ser 270:103-116

Goss R, Lepetit B (2015) Biodiversity of NPQ. J Plant Physiol 172:13-32

Graham LE, Wilcox LW (2000) Algae. Prentice Hall, Upper Saddle River

Grant BR, Wright SW (1980) Purity of chloroplasts prepared from the siphonous green alga, Caulerpa simpliciuscula, as determined by their ultrastructure and their enzymic content. Plant Physiol 66:130-138

Handrich M, de Vries J, Gould SB, Serôdio J, Christa G (2017) Ulvophyceaen photophysiology and research opportunities. Perspect Phycol 4:83-92
Henley WJ (1992) Growth and photosynthesis of Ulva rotundata (Chlorophyta) as a function of temperature and square wave irradiance in indoor culture. J Phycol 28:625-634

Henley WJ, Levavasseur G, Franklin LA, Lindley ST, Ramus J, Osmond CB (1991) Diurnal responses of photosynthesis and fluorescence in Ulva rotundata acclimated to sun and shade in outdoor culture. Mar Ecol Prog Ser 75:19-28

Hohmann-Marriott MF, Blankenship RE (2011) Evolution of photosynthesis. Annu Rev Plant Biol 62:515-548

Holzinger A, Herburger K, Kaplan F, Lewis LA (2015) Desiccation tolerance in the chlorophyte green alga Ulva compressa: does cell wall architecture contribute to ecological success? Planta 242:477-492

Horton P, Ruban AV (1993) $\Delta \mathrm{pH}$-dependent quenching of the Fo level of chlorophyll fluorescence in spinach leaves. Biochim Biophys Acta 1142:203-206

Hurd CL, Harrison PJ, Bischof K, Lobban CS (2014) Seaweed ecology and physiology, 2nd edn. Cambridge University Press, Cambridge

Ikeuchi M, Inoue Y (1988) A New 4.8-kDa polypeptide intrinsic to the PS II reaction center, as revealed by modified SDS-PAGE with improved resolution of low-molecular-weight proteins. Plant Cell Physiol 29:1233-1239

Johnson MP, Ruban AV (2011) Restoration of rapidly reversible photoprotective energy dissipation in the absence of PsbS protein by enhanced $\Delta \mathrm{pH}$. J Biol Chem 286:19973-19981

Kirk JTO (2011) Light and photosynthesis in aquatic ecosystems, 3rd edn. Cambridge University Press, Cambridge

Krause GH, Behrend U (1986) $\Delta \mathrm{pH}$-dependent chlorophyll fluorescence quenching indicating a mechanism of protection against photoinhibition of chloroplasts. FEBS Lett 200:298-302

Krause GH, Weis E (1991) Chlorophyll fluorescence and photosynthesis: the basics. Annu Rev Plant Phys 42:313-349

Laemmli UK (1970) Cleavage of structural proteins during assembly of the head of bacteriophage T4. Nature 227:680-685

Lam DW, Zechman FW (2006) Phylogenetic analyses of the Bryopsidales (Ulvophyceae, Chlorophyta) based on RUBISCO large subunit gene sequences. J Phycol 42:669-678

Lepetit B, Sturm S, Rogato A, Gruber A, Sachse M, Falciatore A, Kroth PG, Lavaud J (2013) High light acclimation in the secondary plastids containing diatom Phaeodactylum tricornutum is triggered by the redox state of the plastoquinone pool. Plant Physiol 161:853-865

Lepetit B, Gélin G, Lepetit M, Sturm S, Vugrinec S, Rogato A, Kroth PG, Falciatore A, Lavaud J (2016) The diatom Phaeodactylum tricornutum adjusts nonphotochemical fluorescence quenching capacity in response to dynamic light via fine-tuned Lhcx and xanthophyll cycle pigment synthesis. New Phytol 214:205-218

Li X-P, Björkman O, Shih C, Grossman AR, Rosenquist M, Jansson S, Niyogi KK (2000) A pigment-binding protein essential for regulation of photosynthetic light harvesting. Nature 403:391-395

Li X-P, Gilmore AM, Caffarri S, Bassi R, Golan T, Kramer D, Niyogi KK (2004) Regulation of photosynthetic light harvesting involves intrathylakoid lumen $\mathrm{pH}$ sensing by the PsbS protein. J Biol Chem 279:22866-22874

Li Z, Wakao S, Fischer BB, Niyogi KK (2009) Sensing and responding to excess light. Annu Rev Plant Biol 60:239-260

Liu Z, Yan H, Wang K, Kuang T, Zhang J, Gui L, An X, Chang W (2004) Crystal structure of spinach major light-harvesting complex at $2.72 \AA$ resolution. Nature 428:287-292

Madsen TV, Maberly SC (1990) A comparison of air and water as environments for photosynthesis by the intertidal alga Fucus spiralis (Phaeophyta). J Phycol 26:24-30

Mou S, Zhang X, Dong M, Fan X, Xu J, Cao S, Xu D, Wang W, Ye N (2013) Photoprotection in the green tidal alga Ulva prolifera: role of LHCSR and PSBSS proteins in response to high light stress. Plant Biol 15:1033-1039 
Nakayama K, Okada M (1990) Purification and characterization of light-harvesting chlorophyll $a / b$-protein complexes of photosystem II from the green alga, Bryopsis maxima. Plant Cell Physiol 31:253-260

Noctor G, Ruban AV, Horton P (1993) Modulation of $\Delta \mathrm{pH}$-dependent nonphotochemical quenching of chlorophyll fluorescence in spinach chloroplasts. Biochim Biophys Acta 1183:339-344

Oxborough K, Baker NR (1997) Resolving chlorophyll $a$ fluorescence images of photosynthetic efficiency into photochemical and nonphotochemical components - calculation of $q_{\mathrm{p}}$ and $F_{\mathrm{v}}{ }^{\prime} / F_{\mathrm{m}}{ }^{\prime}$ without measuring $\mathrm{Fo}^{\prime}$. Photosynth Res 54:135-142

Peers G, Truong TB, Ostendorf E, Busch A, Elrad D, Grossman AR, Hippler M, Niyogi KK (2009) An ancient light-harvesting protein is critical for the regulation of algal photosynthesis. Nature 462:518-521

Pinnola A, DallOsto L, Gerotto C, Morosinotto T, Bassi R, Alboresi A (2013) Zeaxanthin binds to light-harvesting complex stressrelated protein to enhance nonphotochemical quenching in Physcomitrella patens. Plant Cell 25:3519-3534

Platt T, Gallegos CL, Harrison WG (1980) Photoinhibition of photosynthesis in natural assemblages of marine phytoplankton. J Mar Res 38:687-701

Porra RJ, Thompson WA, Kriedemann PE (1989) Determination of accurate extinction coefficients and simultaneous-equations for assaying chlorophylls $a$ and $b$ extracted with 4 different solvents: verification of the concentration of chlorophyll standards by atomic absorption spectroscopy. Biochim Biophys Acta 975:384-394

Provan J, Murphy S, Maggs CA (2004) Tracking the invasive history of the green alga Codium fragile ssp. tomentosoides. Mol Ecol 14:189-194

Qin X, Suga M, Kuang T, Shen JR (2015a) Structural basis for energy transfer pathways in the plant PSI-LHCI supercomplex. Science 348:989-995

Qin X, Wang W, Chang L, Chen J, Wang P, Zhang J, He Y, Kuang T, Shen JR (2015b) Isolation and characterization of a PSI-LHCI super-complex and its sub-complexes from a siphonaceous marine green alga, Bryopsis Corticulans. Photosynth Res 123:61-76

Ruban AV (2012) The photosynthetic membrane: molecular mechanisms and biophysics of light harvesting. Wiley, Chichester. ISBN: 978-1-1199-6053-9

Ruban AV (2016) Nonphotochemical chlorophyll fluorescence quenching: mechanism and effectiveness in protecting plants from photodamage. Plant Physiol 170:1903-1916

Ruban AV, Belgio E (2014) The relationship between maximum tolerated light intensity and photoprotective energy dissipation in the photosynthetic antenna: chloroplast gains and losses. Philos Trans R Soc B 369:20130222

Ruban AV, Murchie EH (2012) Assessing the photoprotective effectiveness of non-photochemical chlorophyll fluorescence quenching: a new approach. Biochim Biophys Acta 1817:977-982

Ruban AV, Johnson MP, Duffy CDP (2011) Natural light harvesting: principles and environmental trends. Energ Environ Sci $4: 1643-1650$
Ruban AV, Johnson MP, Duffy CDP (2012) Photoprotective molecular switch in photosystem II. Biochim Biophys Acta 1817:167-181

Sacharz J, Giovagnetti V, Ungerer P, Mastroianni G, Ruban AV (2017) The xanthophyll cycle affects reversible interactions between PsbS and light-harvesting complex II to control non-photochemical quenching. Nat Plants 3(16225): 1-9

Suga M, Akita F, Hirata K, Ueno G, Murakami H, Nakajima Y, Shimizu T, Yamashita K, Yamamoto M, Ago H, Shen JR (2015) Native structure of photosystem II at $1.95 \AA$ resolution viewed by femtosecond X-ray pulses. Nature 517:99-103

Taddei L, Stella GR, Rogato A, Bailleul B, Fortunato AE, Annunziata R, Sanges R, Thaler M, Lepetit B, Lavaud J, Jaubert M, Finazzi G, Bouly J-P, Falciatore A (2016) Multisignal control of expression of the LHCX protein family in the marine diatom Phaeodactylum tricornutum. J Exp Bot 67:3939-3951

Tibiletti T, Auroy P, Peltier G, Caffarri S (2016) Chlamydomonas reinhardtii PsbS protein is functional and accumulates rapidly and transiently under high light. Plant Physiol 171:2717-2730

Tyystjärvi E, Aro EM (1996) The rate constant of photoinhibition, measured in lincomycin-treated leaves, is directly proportional to light intensity. Proc Natl Acad Sci USA 93:2213-2218

Umena Y, Kawakami K, Shen JR, Kamiya N (2011) Crystal structure of oxygen-evolving photosystem II at a resolution of $1.9 \AA$. Nature 473:55-60

Verbruggen H, Ashworth M, LoDuca ST, Vlaeminck C, Cocquyt E, Sauvage T, Zechman FW, Littler DS, Littler MM, Leliaert F, De Clerck O (2009) A multi-locus time-calibrated phylogeny of the siphonous green algae. Mol Phylogenet Evol 50:642-653

Wang Y, Wang Y, Zhu L, Zhou B, Tang X (2012) Comparative studies on the ecophysiological differences of two green tide macroalgae under controlled laboratory conditions. PLoS One 7:e38245

Wang W, Qin X, Sang M, Chen D, Wang K, Lin R, Lu C, Shen J-R, Kuang T (2013) Spectral and functional studies on siphonaxanthin-type light harvesting complex of photosystem II from Bryopsis corticulans. Photosynth Res 117:267-279

Ware AM, Belgio E, Ruban AV (2015) Photoprotective capacity of non-photochemical quenching in plants acclimated to different light intensities. Photosynth Res 126:261-274

Wraight CA, Crofts AR (1970) Energy-dependent quenching of chlorophyll $a$ fluorescence in isolated chloroplasts. Eur J Biochem 17:319-327

Yamamoto HY (1979) Biochemistry of the violaxanthin cycle in higher plants. Pure Appl Chem 51:639-648

Yamamoto HY, Kamite L (1972) The effects of dithiothreitol on violaxanthin de-epoxidation and absorbance changes in the 500-nm region. Biochim Biophys Acta 267:538-543

Yamazaki J, Suzuki T, Maruta E, Kamimura Y (2005) The stoichiometry and antenna size of the two photosystems in marine green algae, Bryopsis maxima and Ulva pertusa, in relation to the light environment of their natural habitat. J Exp Bot 56:1517-1523

Zhang X, Ye N, Liang C, Mou S, Fan X, Xu J, Xu D, Zhuang Z (2012) De novo sequencing and analysis of the Ulva linza transcriptome to discover putative mechanisms associated with its successful colonization of coastal ecosystems. BMC Genom 13:565 